\title{
Sugar-sweetened beverages induced metabolic syndrome and its reversal using bitter melon extract
}

\author{
Akshay Kirthan Jagannath Peraje, Ananda Puttaiah, Anshu Kumar Yadav, Akila Prashant, \\ Prashant Vishwanath ${ }^{*}$ \\ Centre of Excellence in Molecular Biology and Regenerative Medicine, Department of Biochemistry, JSS Medical College, JSS Academy of \\ Higher Education \& Research, Mysuru-570015, Karnataka, India
}

Received 20th April 2021 / Accepted 2nd July 2021

\begin{abstract}
Sugar-sweetened beverages (SSBs) are known to cause metabolic pathologies increasing the risk for Type 2 diabetes mellitus and cardiovascular disorders. We aimed to determine the effects of chronic sugar intake on lipogenesis and glucose metabolism in mice and study if bitter melon extract (BME) can reverse this effect. BME was prepared using 50\% ethanol as solvent, biochemical assays for the estimation of phenolic compounds, antioxidant, and anti-inflammatory activity was performed. Male Swiss albino mice were divided into seven groups $(n=6)$ : Control (group-1), Glucose (group-2), Glucose+BME (group-3), Sucrose (group-4), Sucrose+BME (group-5), Fructose (group-6), Fructose+BME (group-7). Each group was induced with 30\% wt/vol of respective sugars for 8 weeks, and BME was supplemented (300 mg/kg body weight) to group-3, 5, and 7 along with sugars after 4 weeks of induction. Blood glucose and body weight measurements were performed every week for 8 weeks. Animals were sacrificed and retroperitoneal adipose tissue (RPAT) was collected along with blood for lipid profile estimation. RPAT was stained with hematoxylin \& eosin and examined under the microscope for adipocyte cell count/size. Group-3, 5, and 7 presented a significant decrease in the body weight at 8th week when compared to their 4th-week bodyweight, a significant drop in blood glucose and all the lipid profile parameters when compared to their respective control groups, and group-3 and 5 presented a significant reduction in the size of the adipocyte upon treatment with BME. Due to the presence of high phenolic acids, antioxidants, and anti-inflammatory property BME has various health benefits and the potential to treat SSB-induced metabolic disorders.
\end{abstract}

Keywords: bitter melon extract, lipid profile, adipocyte hypertrophy, male Swiss albino mice, sugarsweetened beverages

\section{INTRODUCTION}

In recent times, numerous manufactured food products contain high sucrose or fructose corn syrup contributing to their sugar content. Sugarsweetened beverages (SSBs) are the major source of added sugars in the diet adding up to $7 \%$ of the daily calories (Kit et al., 2013). Several reports have shown a strong correlation between SSB consumption and excessive weight gain and obesity (Hannou et al., 2018). SSBs increase visceral adiposity predisposing an individual to cardiometabolic risk. This important source of energy in our diet is usually present in the form of glucose or fructose, either alone or in combination in the form of sucrose. Hence, it is essential to study the effect of high glucose and fructose individually and in combination in the form of sucrose.

*Author for correspondence: Centre of Excellence in Molecular Biology and Regenerative Medicine, Department of Biochemistry, JSS Medical College, JSS Academy of Higher Education \& Research, Mysuru-570015, Karnataka, India.Email - prashantv@jssuni.edu.in 
Animals fed with increased quantities of fructose can rapidly develop several features of metabolic syndrome that include obesity, deranged lipid profile, peripheral resistance to insulin, fatty liver, raised blood pressure, and blood sugar levels (Thorburn et al., 1989). Studies have also shown that consuming large amounts of sucrose shows an increase in energy intake, fat mass, body weight, and blood pressure after 10 weeks of consumption (Raben et al., 2002). When compared to glucose and other complex carbohydrates, fructose consumption results in reduced postprandial glycemic and insulin excursion. As a result, fructose was once believed to be advantageous in the management of insulin resistance and Type 2 diabetes mellitus. However, recently it has been alleged to be more damaging than other sugars.

Fructose is absorbed from the intestine by facilitated diffusion using fructose transporter GluT5. For unknown reasons, there is a significant increase in the rate of absorption when fructose is co-ingested with the same amounts of glucose (Truswell, Seach and Thorburn, 1988). The ingested fructose is mainly metabolized by the liver and bypasses the tightly regulated, ratelimiting step of glycolysis, the phosphofructokinase step. This is the explanation for why glucose and fructose have distinct metabolic effects (Kolderup and Svihus, 2015). Intake of fructose may also lead to the formation of fatty acids via de novo lipogenesis (DNL) (Stanhope, 2016). DNL boosts the intra-hepatic lipid supply that stimulates very-low-density lipoprotein (VLDL) production and secretion, which in turn leads to increased levels of postprandial triglyceride (TG) and dyslipidemia (Adiels et al., 2008). High fructose intake contributes adversely to blood glucose regulation by triggering insulin resistance (Sievenpiper et al., 2014). The increase in serum insulin and leptin levels and decrease in ghrelin levels post high fructose diet is less when compared to a high glucose diet, resulting in excess food consumption, weight gain ultimately leading to cardiometabolic complications (Bray, 2013).

In recent years, research is heading towards mitigating the harmful effects of high sugars either in terms of reduction of body weight or improvement in the metabolic parameters. Insulin sensitizing agents like glitazones and biguanides are commonly used in the treatment of insulin resistance and to improve metabolic parameters. However, the use of these insulin-sensitizing agents is not free from side effects like bladder cancer, fractures, weight gain, and hepatotoxicity (Krans, 1994). The use of traditional plant-based compounds has been recommended as therapeutic agents to reverse or prevent metabolic disorders due to their increased efficacy, lesser adverse effects, and being readily available and economical (Bayya et al., 2018).

Bitter melon is one such traditional plant that has shown promising results in improving blood glucose levels and reducing lipogenesis and increasing lipolysis both in cell culture-based studies and animal models (Chandru et al., 2016; Shobha et al., 2017). In this study, we aim to establish the effects of chronic glucose and fructose intake on lipogenesis and glucose metabolism in mice and study if bitter melon supplementation can reverse this effect.

\section{MATERIALS AND METHODS}

\section{Extraction of hydro-ethanolic (EtOH) fraction of bitter melon extract (BME)}

Taxonomically authenticated unripe bitter melon fruits were washed with distilled water and coarsely minced before making a fine paste using a household mixer grinder which was later subjected to freeze dry (lyophilisation) using the lyophilizer. The lyophilized powdered fruit was used for preparing 50\% hydro-ethanolic soluble fractions using a magnetic stirrer. After 8 hours of extraction by magnetic stirring at room temperature, the flask with partially extracted plant material was stored overnight inside the refrigerator for percolation of respective soluble fractions. The following day, the extracts were cold centrifuged at $5000 \mathrm{rpm}$ for 10 minutes and filtered using Whatman's filter paper to separate soluble fractions in the supernatant and stored at $-20^{\circ} \mathrm{C}$ deep freezer. The whole process was repeated with the pellet 3 times on 3 subsequent days and was carried out with minimum exposure to light. The fractions were further concentrated using a vacuum concentrator programmed for volatile/low-volatile extracts at an operating temperature of $45^{\circ} \mathrm{C}$. After concentration for 8 
hours, the extracts were frozen at $-80^{\circ} \mathrm{C}$ and subjected to final lyophilization to obtain a fine lyophilized powder. The powder was stored in an amber-colored airtight container for further analytical studies.

\section{Solubility analysis of lyophilized extracts}

The 50\% EtOH BME lyophilized powder was subjected to solubility analysis for defined concentration $(10 \mathrm{mg} / \mathrm{ml})$ using various solvents so that the compound can be efficiently dissolved for in vivo studies. The vehicle solvent was chosen carefully after reviewing the literature for their toxicity in the animal model (Swiss albino mice) used in the study. We learned that 10\% Dimethyl sulfoxide (DMSO) was optimal and non-toxic to the animal model when administered as a vehicle for 4 weeks (Gad and Sullivan, 2014). Distilled water, ethanol, phosphate buffer saline, and 1\% carboxymethyl cellulose were found to be insoluble at $10 \mathrm{mg} / \mathrm{ml}$ of the compound. Hence, DMSO was chosen and was screened for solubility at different concentrations (higher to lower).

\section{Phytochemical (biochemical) analysis}

The total phenol content of the prepared extract was estimated by Folin-Ciocalteu (FC) Method using gallic acid as standard and results were expressed in gallic acid equivalent/gm of dry extract. The total carbohydrate available was estimated by the phenol sulfuric acid method, the total reducing sugars were estimated by 3, 5Dinitrosalicylic Acid method, and total glucose content was measured by glucose oxidaseperoxidase (GOD-POD) method all using glucose as standard. The antioxidant activity of the extract was measured by ferric reducing antioxidant power analysis (FRAP) using ferrous sulfate as standard and results were expressed as $\mu \mathrm{mol}$ of $\mathrm{FeSO}_{4}$ equivalents (FRAP units). The free radical scavenging activity was measured by the 2, 2-diphenyl-1-picrylhydrazyl (DPPH) method using ascorbic acid as standard and was expressed as the percentage inhibition (\%I). The IC-50 value was calculated from the plot of inhibition (\%) using graph pad prism software. The soluble phenolic fractions were analyzed spectrophotometrically by scanning the extracts between the wavelength ranging from $220 \mathrm{~nm}$ to $400 \mathrm{~nm}$. To assess the anti-inflammatory activity
(AIA) of the extract, a hypotonicity induced Human Red Blood Cell (HRBC) membrane stabilization assay was carried out.

\section{Animal model for in vivo studies}

Male Swiss albino mice (2 weeks old with an average body weight of $20 \mathrm{gms}$ ) were procured from Biogene- Laboratory Animal Facility Centre, Bangalore after obtaining necessary approval from the Institutional Animal Ethics Committee (CPCSEA Reg. no: 971/PO/RcBIBt/S/2006/ CPCSEA). Upon receipt, the animals were caged and acclimatized in the central animal house facility of the institution under controlled conventional conditions following the Committee for Control and Supervision of Experiments on Animals (CPCSEA) guidelines for 3 weeks. Animals were kept in cages made up of autoclavable polypropylene material (Cage dimension $290 \mathrm{~cm} \times 220 \mathrm{~cm} \times 140 \mathrm{~cm}$ with thickness $4 \mathrm{~mm} \pm 0.5$ ) with an accessible floor of $380 \mathrm{~cm}^{2}$ and continuous access to hygienic food and purified drinking water. Ad libitum feeding of standard diet in the form of pellet chow containing the nutritional requirement for different stages of growth and development was provided to the mice. Cages were maintained in a well-ventilated room having a favorable environment as recommended under Institute for Laboratory Animal Research (ILAR) 2011 guidelines (Temp $25-28^{\circ} \mathrm{C}$, Humidity $45-50 \%$, photoperiod 12:12 hours of light: dark cycle). Regular maintenance and cleaning of the cage were done once in 3 days which included changing the beddings and cage decontamination. Rice husk (0.5-inch-thick) was used as contact bedding for mice maintained within the cage. The cages were decontaminated with $70 \%$ ethanol every time the bedding was changed.

\section{Induction of lipogenesis and treatment with 50\%EtOH BME}

The mice were maintained in the animal house for 4 weeks before initiating the experiment. A total of 42 mice were randomly grouped into 7 groups as shown in Table 1 with each group containing 6 mice each that were almost comparable for their weight and eating habits. The control group (Group 1) mice had ad libitum access to water and chow for 8 weeks. The remaining 6 groups of mice were subjected to sugar-induced lipogenesis 
for the 1st four weeks. 3 types of sugars including Glucose (G), Sucrose (S), and Fructose (F) were prepared as 30\% wt/vol solution with $\mathrm{D} / \mathrm{W}$ and provided to group 2, 4, and 6 of mice along with ad libitum access to standard chow for 8 weeks to induce fat production (lipogenesis). The mice in group 3, 5, and 7 were treated as above for 8 weeks, however, after the 4th week, a single midday oral dose of $300 \mathrm{mg} / \mathrm{kg}$ body weight of
$50 \%$ EtOH BME prepared in 10\% DMSO (10 $\mathrm{mg} / \mathrm{ml}$ ) was introduced via oropharyngeal route using oral gavage needle (Saeed et al., 2021). The alterations in blood glucose (fasting blood glucose) using a glucometer by the collection of tail vein blood and body weight were evaluated at the end of every week and compared with that of the control un-induced, untreated mice.

Table 1. Animal groupings and group characteristics.

\begin{tabular}{|c|c|c|c|c|}
\hline $\begin{array}{l}\text { Group } \\
\text { No }\end{array}$ & $\begin{array}{l}\text { Group } \\
\text { Name } \\
(n=6)\end{array}$ & Group codes & Group characteristics & Duration (weeks) \\
\hline 1 & Control & $\begin{array}{l}\text { Un-induced } \\
\text { untreated control } \\
\text { (C) }\end{array}$ & $\begin{array}{l}\text { Ad libitum access to water and } \\
\text { chow }\end{array}$ & 8 weeks \\
\hline 2 & & $\begin{array}{l}\text { Glucose-control } \\
(\mathrm{G})\end{array}$ & $30 \%$ glucose solution with chow & 8 weeks (induction) \\
\hline 3 & Glucose & $\begin{array}{l}\text { Glucose }+ \text { BME } \\
\text { treatment }(\mathrm{GB})\end{array}$ & $\begin{array}{l}30 \% \text { glucose solution with chow } \\
\text { and } 50 \% \mathrm{BME}(0.5 \mathrm{ml})\end{array}$ & $\begin{array}{l}4 \text { weeks (induction) / } 4 \\
\text { weeks induction with } \\
\text { treatment }\end{array}$ \\
\hline 4 & & $\begin{array}{l}\text { Sucrose-control } \\
\text { (S) }\end{array}$ & $30 \%$ sucrose solution with chow & 8 weeks (induction) \\
\hline 5 & Sucrose & $\begin{array}{l}\text { Sucrose }+\mathrm{BME} \\
\text { treatment }(\mathrm{SB})\end{array}$ & $\begin{array}{l}30 \% \text { sucrose solution with chow } \\
\text { and } 50 \% \mathrm{BME}(0.5 \mathrm{ml})\end{array}$ & $\begin{array}{l}4 \text { weeks (induction)/ } 4 \\
\text { weeks induction with } \\
\text { treatment }\end{array}$ \\
\hline 6 & & $\begin{array}{l}\text { Fructose-control } \\
\text { (F) }\end{array}$ & $30 \%$ fructose solution with chow & 8 weeks induction \\
\hline 7 & Fructose & $\begin{array}{l}\text { Fructose }+ \text { BME } \\
\text { treatment }(\mathrm{FB})\end{array}$ & $\begin{array}{l}30 \% \text { fructose solution with chow } \\
\text { and } 50 \% \text { BME }(0.5 \mathrm{ml})\end{array}$ & $\begin{array}{l}4 \text { weeks (induction) / } 4 \\
\text { weeks induction with } \\
\text { treatment }\end{array}$ \\
\hline
\end{tabular}

BME - Bitter melon extract

\section{Animal sacrifice and collection of blood and adipose tissue}

At the end of the study, i.e. after 8 weeks, the animals were sacrificed by the chemical method using Diethyl ether. The mice were dissected aseptically from the midventral region of the body through the mid-abdominal and thoracic lines, gently puncturing the thoracic cavity. $1 \mathrm{ml}$ tuberculin syringe with a $27 \mathrm{G}$ needle was used for a cardiac puncture to collect a blood sample from the posterior as well as the anterior region of the heart along with the apical region. The blood was transferred to plain vacutainers and allowed to clot for 30 minutes followed by serum separation by centrifugation at $3000 \mathrm{rpm}$ for 10 minutes. Serum samples were used for the analysis of lipid profiles using a semi-automated kit-based method from Agappe Diagnostics. Total cholesterol (TC) was estimated by Zak's method, Triglycerides (TG) by Glycerol phosphate oxidase method, High-density Lipoprotein (HDL) by Selective Inhibition method, and Low-density Lipoprotein (LDL) and Very-Low Density Lipoprotein (VLDL) by calculation.

Adipose tissue was collected from the retroperitoneal region of the animal and immediately fixed in 10\% formalin and further processed for preparation of histo-pathological slides. The microscopic examination of H\&E stained retroperitoneal adipose tissue (RPAT) sections were studied using Bright Field Microscopy (Olympus). The number and size of 
the adipocytes were analyzed in all the sample groups and changes in the pattern among the treated and the control groups were elucidated using image J software along with Cell Sense dimension software integrated with the Bright Field Microscope (Olympus).

\section{Statistical analysis}

MS excel -2010 was used to enter the collected data which was analyzed using SPSS version 24. Descriptive statistical measures like percentage, mean, and standard deviation were applied. Inferential statistical analysis was done using oneway ANOVA for cell counts, cell size, and lipid profile parameters. Repeated measures ANOVA was applied for the assessment of the difference between mean body weight and blood glucose levels throughout follow-up. Bonferroni's post hoc test was applied to understand the group which was most significantly different from the rest of the groups. The differences were interpreted as statistically significant at $P<0.05$.

\section{RESULTS}

\section{Phytochemical (biochemical) analysis}

The total phenol content in $50 \% \mathrm{EtOH}$ of $\mathrm{BME}$ was $32.6 \pm 0.2 \mathrm{GAE} / \mathrm{gm}$ of extract, the total carbohydrate content was $16.55 \pm 0.04 \mathrm{mg} / \mathrm{ml}$ $(1,655 \mathrm{mg} / \mathrm{dl})$, the total reducing sugar was $72.18 \pm 1.2 \mathrm{mg} / \mathrm{dl}$ and the total glucose content was $8.3 \pm 2.6 \mathrm{mg} / \mathrm{dl}$. The antioxidant activity by the FRAP method showed that $50 \% \mathrm{EtOH}$ of BME had antioxidant activity equivalent to $625 \pm 5$ $\mu \mathrm{mol}$ of $\mathrm{FeSO}_{4}$ equivalent. The free radical scavenging activity by the DPPH method revealed that $50 \%$ EtOH of BME had an inhibitory activity of $26 \%$ with IC50 of $62.7 \pm 2.3 \mu \mathrm{g} / \mathrm{ml}$. These activities are higher than those reported in the previous studies suggesting good antioxidant property of the prepared extract $(\mathrm{Ng}$ and Kuppusamy, 2019). Upon spectrometric analysis of phenolic fractions, the absorption spectra of $50 \% \mathrm{EtOH}$ of $\mathrm{BME}$ corresponded to that of gallic acid with peak absorption at $264 \mathrm{~nm}$. The 50\% $\mathrm{EtOH}$ of $\mathrm{BME}$ showed significant stabilization towards HRBC membranes. The percentage of protection was found to be $86 \pm 0.43 \%$ which was
$6 \%$ more than that of the standard drug diclofenac (Aspirin $1 \mathrm{mg} / \mathrm{ml}$ ).

\section{Induction of lipogenesis and treatment with 50\%EtOH BME}

There was a gradual increase in the weight of the mice in all the study groups including the control group in the first four weeks during induction with respective sugar beverages (Figure 1). The weight gain in the mice supplemented with sucrose and fructose was relatively less when compared to that of the mice supplemented with glucose. However, there was no difference in the amount of food and water intake among any groups. After the 4th week, the body weight in the control group had stabilized and did not show any fluctuation ( $p=0.536)$. Group 3, 5, and 7 treated with BME at a dose of $300 \mathrm{mg} / \mathrm{kg}$ body weight/day from 4th week to 8th week (Figure 2) showed a significant reduction in the body weight at 8th week when compared to their 4th-week body weight ( $p=0.022,0.004,0.027$ respectively).

There was a gradual increase in the blood glucose level of the mice in all the study groups in the first four weeks during induction with respective sugar beverages (Figure 3). There was a significant increase in the blood glucose levels in groups 2, 4, and 6 when compared to the control group from the 4th week to the 8th week ( $\mathrm{p}=$ $0.012,0.001,0.002$ respectively). The increase was highly significant in group 4. However, in groups 3 , 5, and 7 where the mice received BME supplementation, there was a significant reduction in the blood glucose levels at 8 weeks (Figure 4) $(p=0.001,0.001,0.043$ respectively).

There was a significant increase in the total cholesterol $(\mathrm{p}=0.001,0.022$ and 0.0001 respectively) and triglyceride $(\mathrm{p}=0.021,0.032$ and 0.001 respectively) levels in group 2, 4, and 6 when compared to the control group. However, after BME supplementation there was a significant reduction in all the lipid profile parameters [Total Cholesterol ( $\mathrm{p}=0.001,0.001$ and 0.0001 respectively), triglycerides $(\mathrm{p}=0.001,0.001,0.011$ respectively), HDL (0.001, 0.001, 0.001 respectively), LDL ( $p=0.001,0.0001,0.001$ respectively) and VLDL ( $\mathrm{p}=0.001,0.001,0.001$ respectively)] in the groups 3,5 and 7 when compared to their respective control groups (Table 2). 


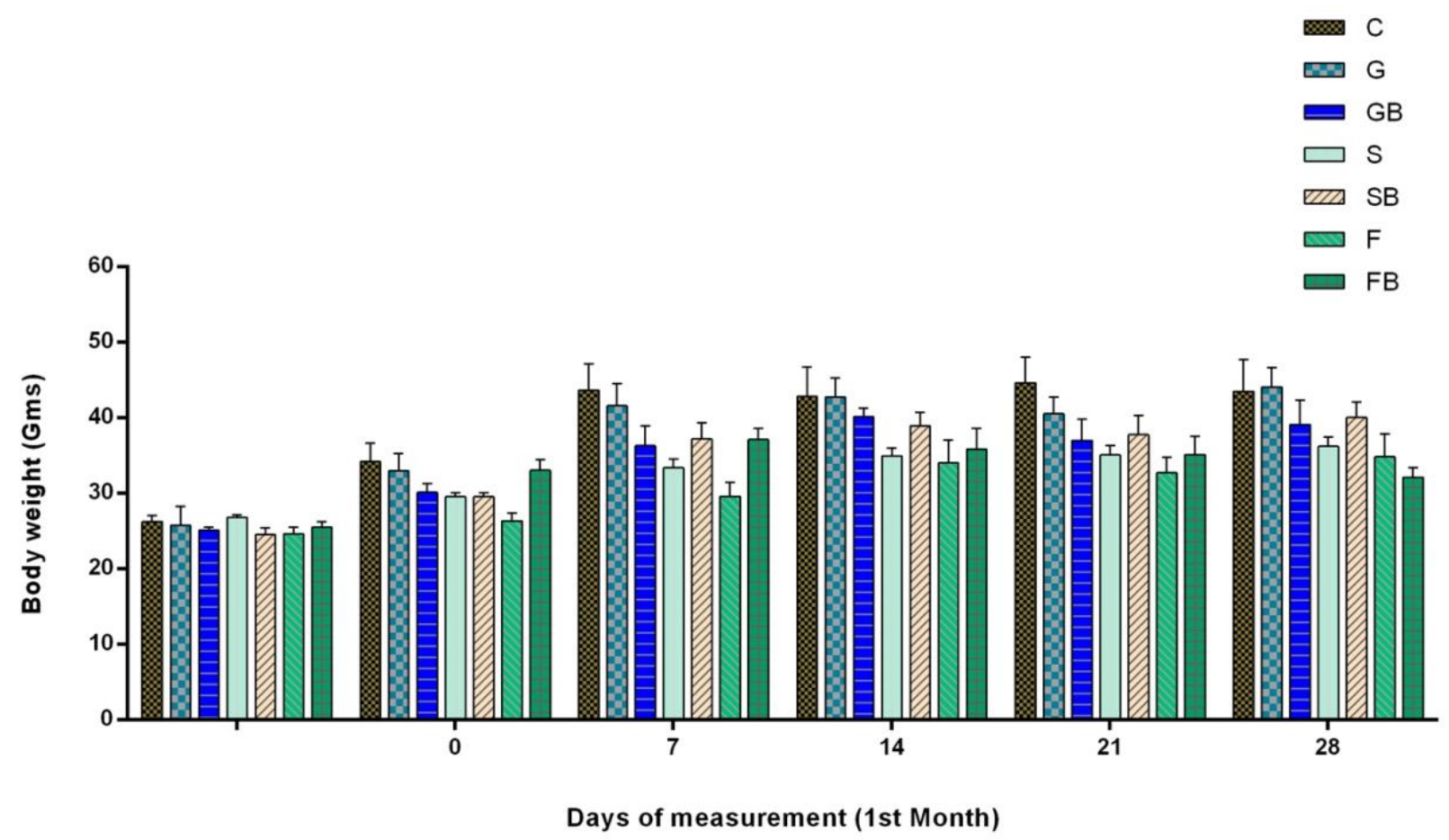

Figure 1. Bodyweight measurement of the mice during the first 4 weeks during induction with respective sugar beverages.

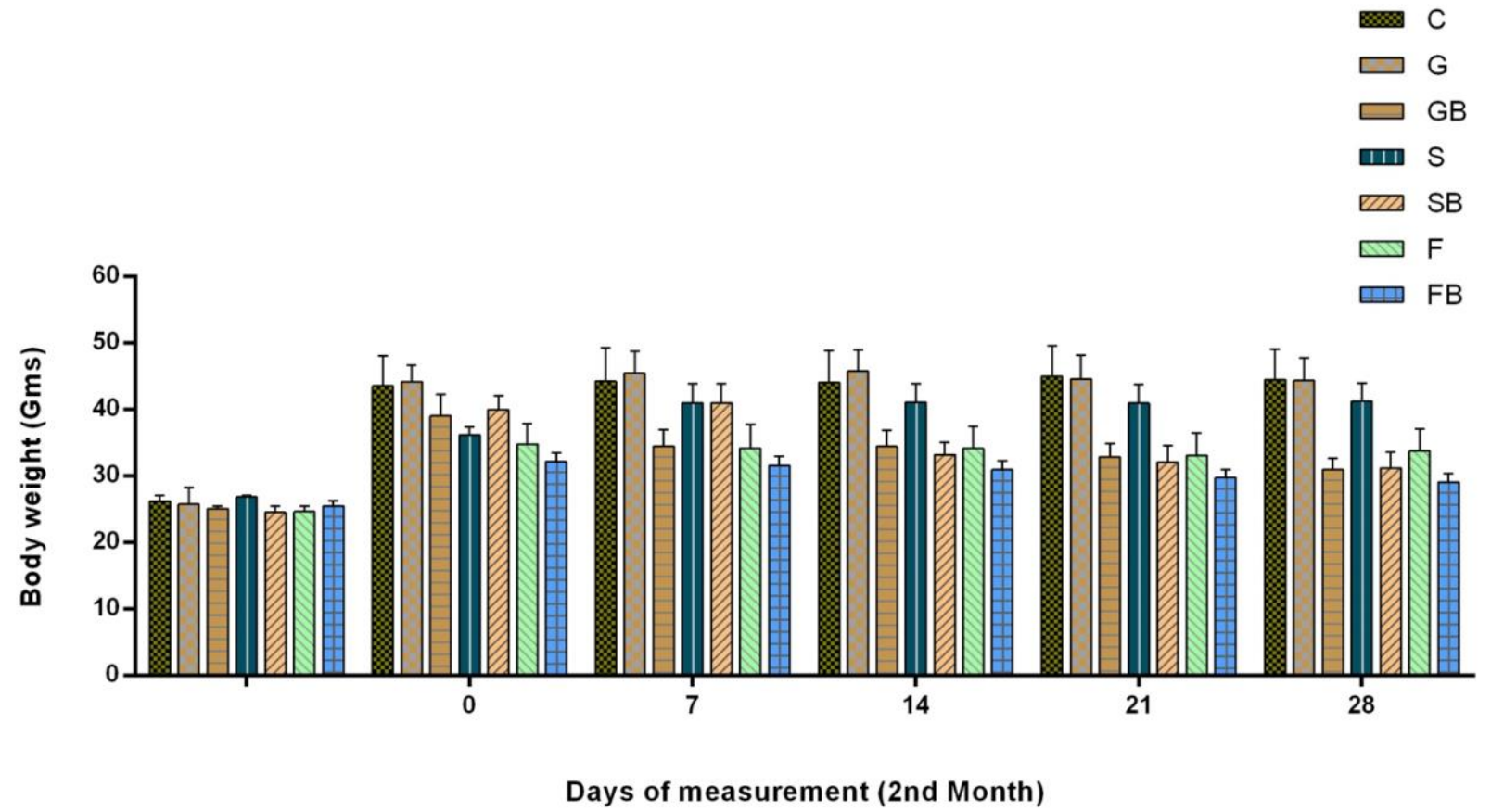

Figure 2. Bodyweight measurement of the mice during the next 4 weeks after supplementing with $50 \%$ $\mathrm{EtOH}$ of BME along with respective sugars. 


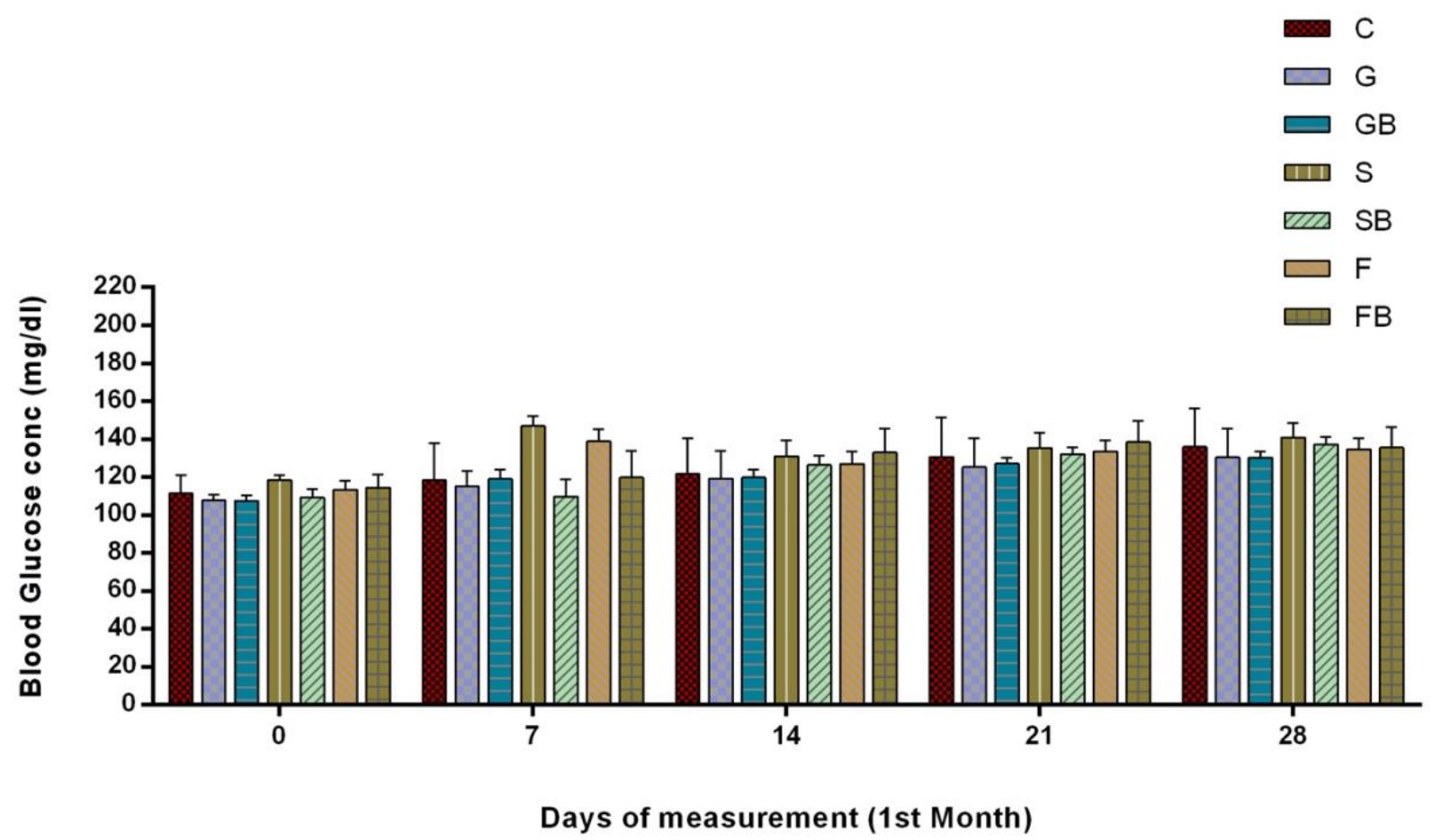

Figure 3. Blood glucose levels in the mice during the first 4 weeks during induction with respective sugar beverages.

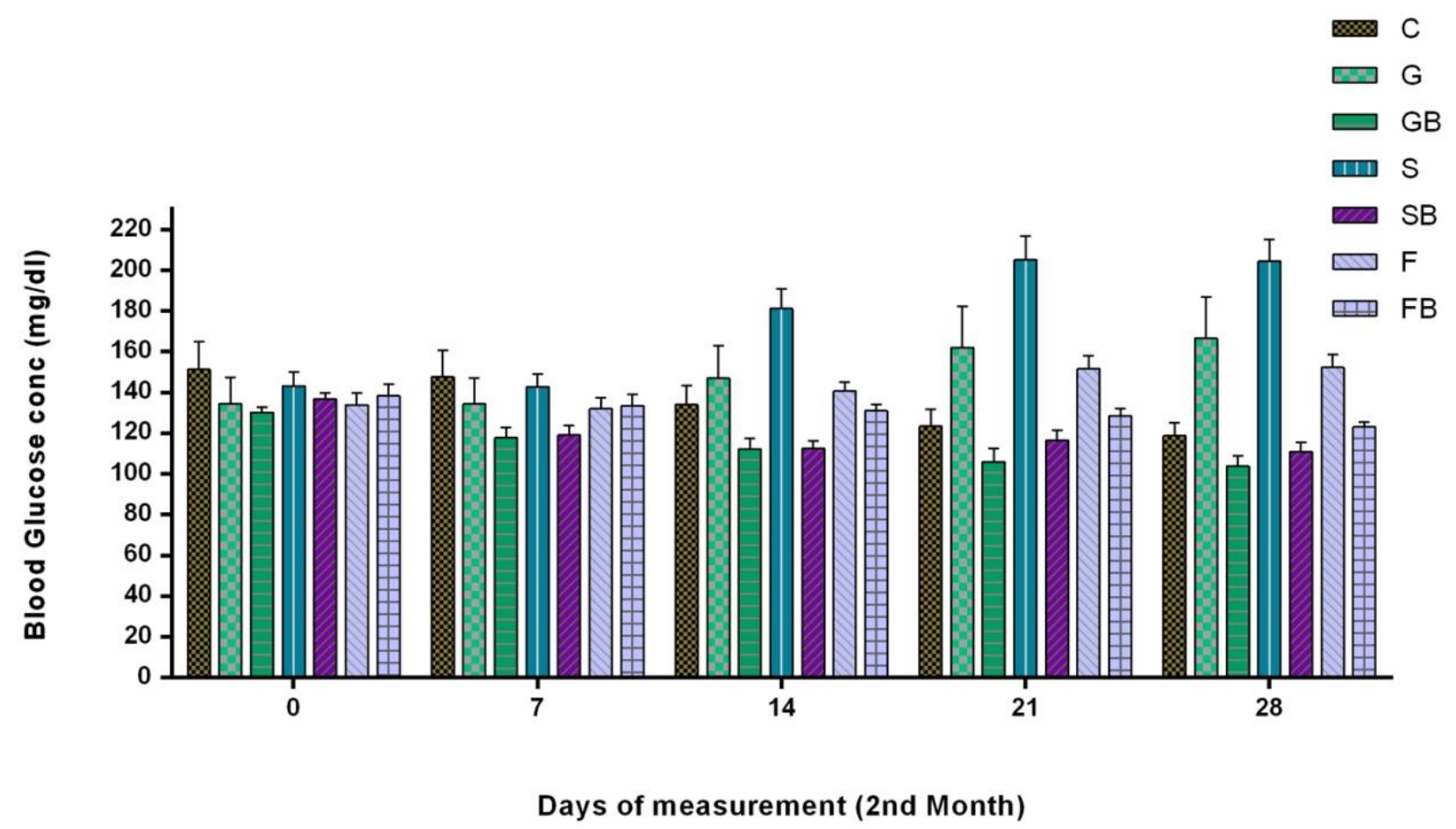

Figure 4. Blood glucose levels in the mice during the next 4 weeks after supplementing with $50 \% \mathrm{EtOH}$ of BME. 
Table 2. Average levels lipid profile parameters in the mice of all the groups after 8 weeks.

\begin{tabular}{|c|c|c|c|c|c|c|}
\hline Study groups & $\begin{array}{l}\mathrm{CHOL} \\
\mathrm{mg} / \mathrm{dl}\end{array}$ & $\begin{array}{l}\text { TGL } \\
\mathrm{mg} / \mathrm{dl}\end{array}$ & $\begin{array}{l}\mathrm{HDL} \\
\mathrm{mg} / \mathrm{dl}\end{array}$ & $\begin{array}{c}\mathrm{LDL} \\
\mathrm{mg} / \mathrm{dl}\end{array}$ & $\begin{array}{l}\text { VLDL } \\
\mathrm{mg} / \mathrm{dl}\end{array}$ & CHOL/HDL \\
\hline C (Control) & $144 \pm 14.7$ & $254 \pm 110$ & $32 \pm 3.6$ & $61.2 \pm 12.7$ & $50.8 \pm 22$ & $4.46 \pm 0.05$ \\
\hline G (Glucose) & $162 \pm 9.5^{\#}$ & $266.25 \pm 57.3^{* *}$ & $33 \pm 4.2$ & $75.75 \pm 17.4$ & $53.25 \pm 11.4$ & $4.92 \pm 0.38$ \\
\hline $\begin{array}{c}\text { GB (Glucose } \\
+ \text { BME) }\end{array}$ & $110 \pm 10.3 \$$ & $121.6 \pm 19.9^{\$}$ & $28.2 \pm 2.7 \$$ & $57.48 \pm 11.8^{\$}$ & $24.32 \pm 3.9 \$$ & $3.86 \pm 0.43$ \\
\hline S (Sucrose) & $162.4 \pm 27.1^{* *}$ & $275.6 \pm 147^{* *}$ & $33.6 \pm 6.4$ & $99.04 \pm 21.4$ & $55.12 \pm 29.4$ & $4.84 \pm 0.46$ \\
\hline $\begin{array}{c}\text { SB (Sucrose + } \\
\text { BME) }\end{array}$ & $98.8 \pm 24.8^{\$}$ & $148.8 \pm 13.5^{\$}$ & $25.2 \pm 4.3^{\$}$ & 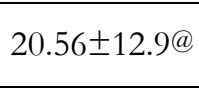 & $29.76 \pm 2.7 \$$ & $3.86 \pm 0.48$ \\
\hline F (Fructose) & $168.8 \pm 32.4^{*}$ & $341.6 \pm 36.6^{\#}$ & $36.2 \pm 5.6$ & $64.28 \pm 23.4$ & $68.32 \pm 7.3$ & $4.62 \pm 0.19$ \\
\hline $\begin{array}{c}\text { FB (Fructose } \\
+ \text { BME) }\end{array}$ & 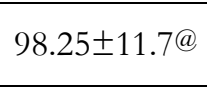 & $185.5 \pm 35.4^{\# \#}$ & $22.75 \pm 1.2^{\$}$ & $38.4 \pm 17.9 \$$ & $37.1 \pm 7.0^{\$}$ & $4.27 \pm 0.40$ \\
\hline
\end{tabular}

$* \mathrm{p}=0.0001$ when compared to the un-induced, untreated controls

$\# \mathrm{p}=0.001$ when compared to the un-induced, untreated controls

(a) $\mathrm{p}=0.0001$ when compared to untreated respective controls

$\$ \mathrm{p}=0.001$ when compared to untreated respective controls

$*^{* *} \mathrm{p}=<0.05$ when compared to the un-induced, untreated controls

\#\# $\mathrm{p}=<0.05$ when compared to untreated respective controls

CHOL-Total Cholesterol, TGL-Triglycerides, HDL-High density lipoproeins, LDL-Low density lipoproteins, VLDL-Very low density lipoproteins

Table 3. Adipocytes cell count \& cell size (CellSense Dimension Software v.16.4).

\begin{tabular}{ccc}
\hline Sample Groups & Cell Count/hpf. & Cell Size (radius in $\boldsymbol{\mu m}) / \mathbf{h p f .}$ \\
\hline C (Control) & $623 \pm 46.87$ & $5.10 \pm 0.06$ \\
G (Glucose) & $165 \pm 4.14^{*}$ & $12.83 \pm 0.06^{*}$ \\
GB (Glucose + BME) & $269 \pm 8.77^{@}$ & $8.74 \pm 0.35^{\S}$ \\
S (Sucrose) & $129 \pm 22.31^{\#}$ & $15.68 \pm 1.17^{\#}$ \\
SB (Sucrose + BME) & $691 \pm 30.55^{@}$ & $4.58 \pm 0.58^{@}$ \\
F (Fructose) & $172 \pm 2.58^{*}$ & $13.43 \pm 0.37^{*}$ \\
FB (Fructose + BME) & $110 \pm 10.86$ & $17.52 \pm 0.58$ \\
\hline
\end{tabular}

hpf - High power field

$* \mathrm{p}=0.0001$ when compared to the un-induced, untreated controls

$\# \mathrm{p}=0.001$ when compared to the un-induced, untreated controls

@ $\mathrm{p}=0.0001$ when compared to untreated respective controls

$\$ p=0.001$ when compared to untreated respective controls

\section{Adipocyte cell count and size evaluation}

The normal adipocyte size and count in $20 \mathrm{X}$ and $40 \mathrm{X}$ is shown in Figures $5 \mathrm{~A}$ and $\mathrm{B}$, respectively. The adipocyte size in the group 2, 4, and 6 was significantly increased when compared to the uninduced, untreated control group $(p=0.0001$, $0.001,0.0001$ respectively) (Figures 6A, 7A, and $8 \mathrm{~A})$. Upon treatment with $\mathrm{BME}$, there was a significant reduction in the size of the adipocyte in groups 3 and 5 ( $p=0.001,0.0001$ respectively) (Figures 6B and 7B). However, in group 7
(Fructose $+\mathrm{BME}$ ) there was no reduction in the size of the adipocyte $(p=0.054)$ (Figure 8B).

Due to an increase in adipocyte size, there was a decrease in the cell count per high power field in groups 2, 4, and 6 when compared to the uninduced, untreated control group $(p=0.0001$, $0.001,0.0001$ respectively). However, the cell count increased in groups 3 and 5 upon treatment with BME ( $\mathrm{p}=0.0001,0.0001$ respectively). The cell count did not improve in group $7(p=0.078)$ (Table 3). 

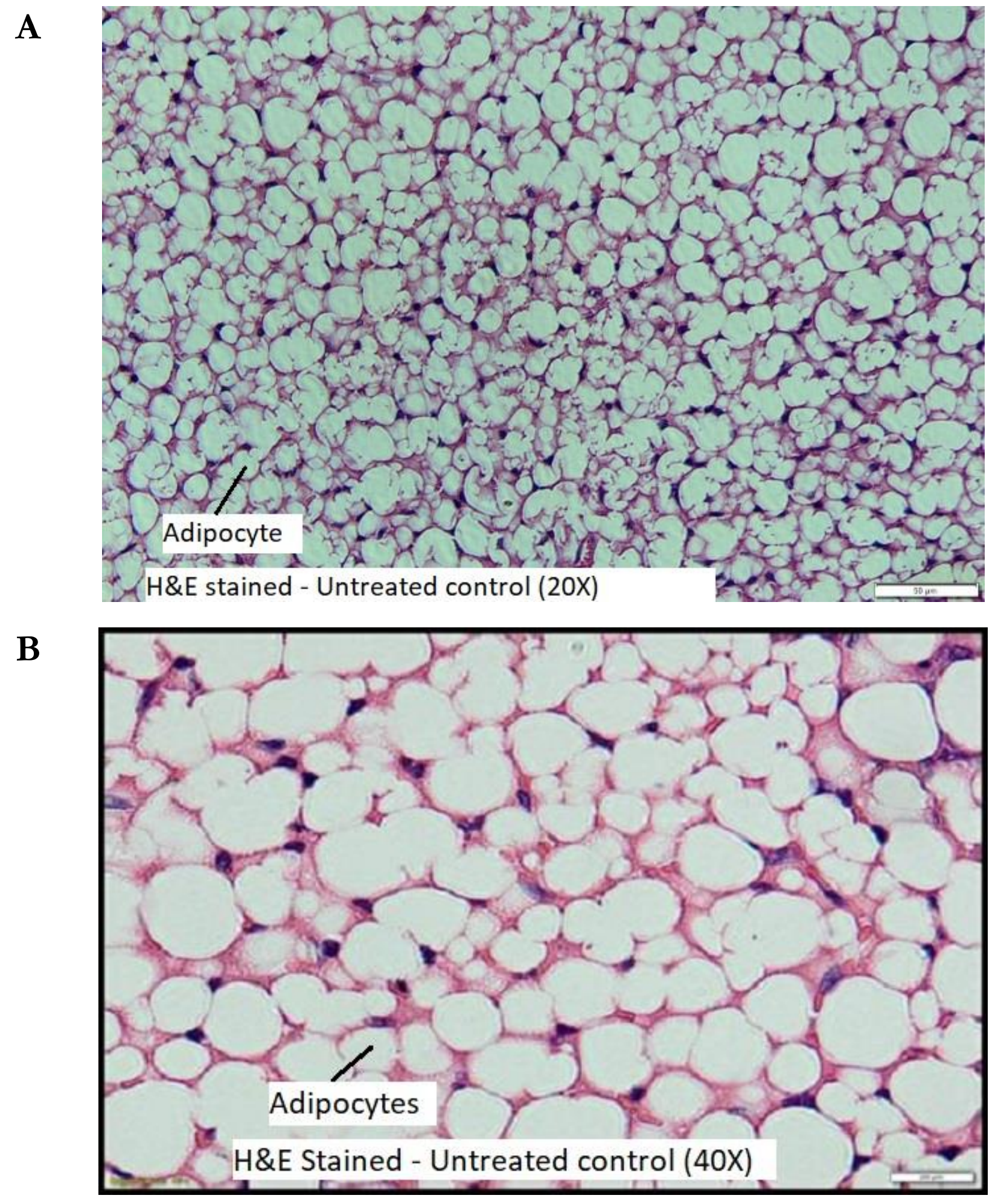

Figure 5. Retroperitoneal adipocyte of un-induced control mice (A) $20 \mathrm{X}$; (B) 40 X. 
A

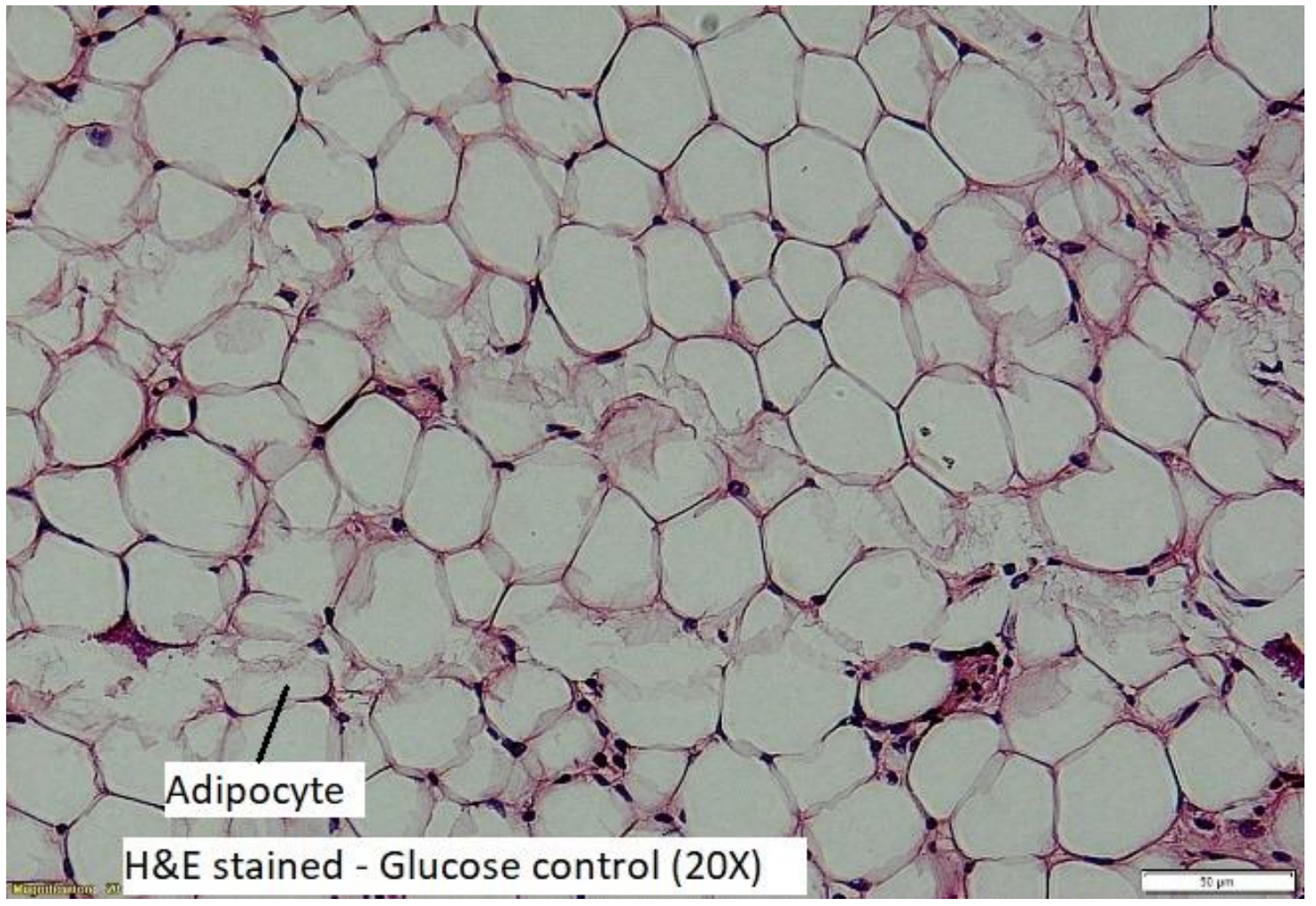

B

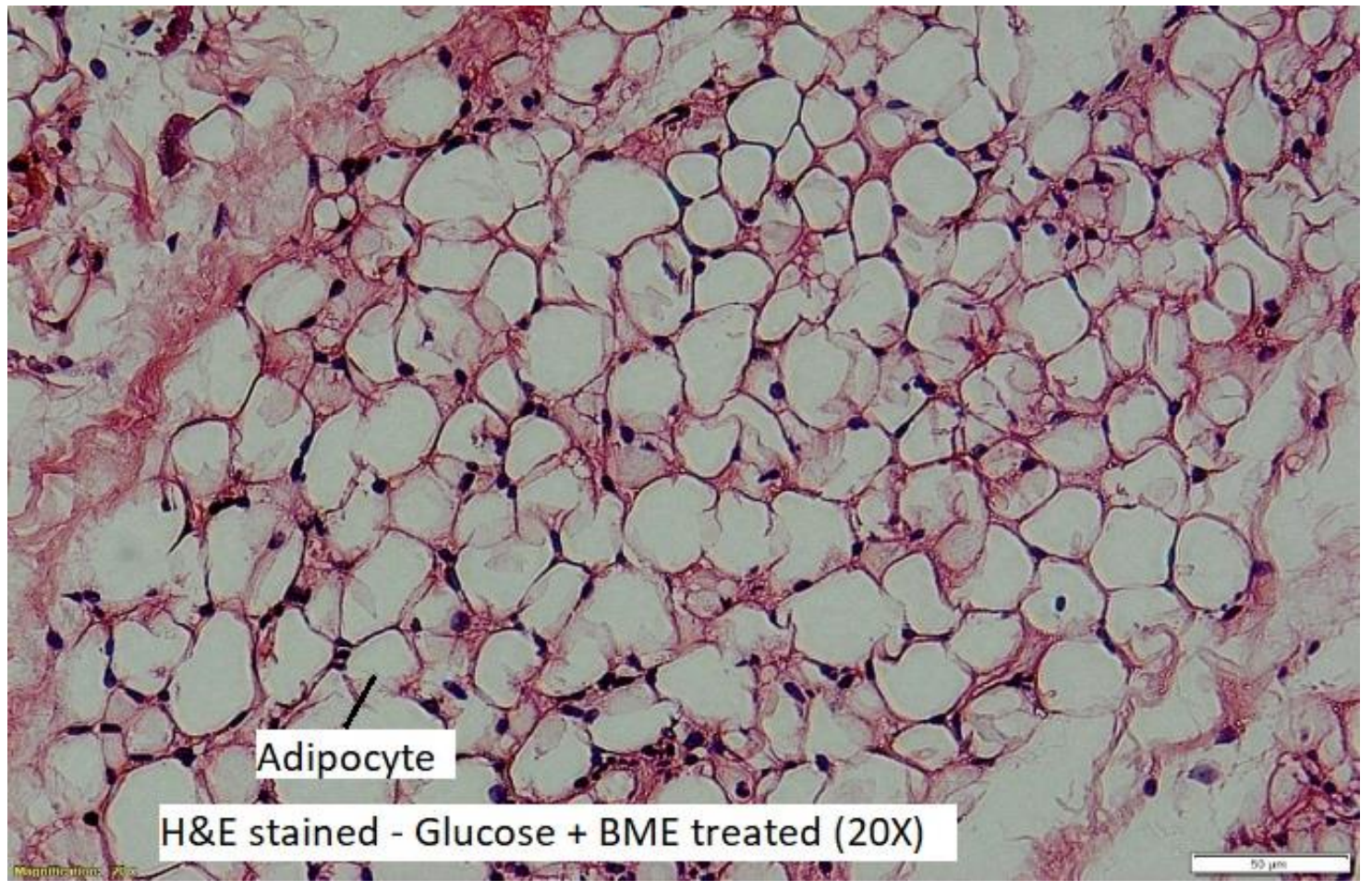

Figure 6. Retroperitoneal adipose tissue of mice treated with a $30 \%$ glucose solution (20 X). (A) without BME supplementation; (B) with BME supplementation. 
A

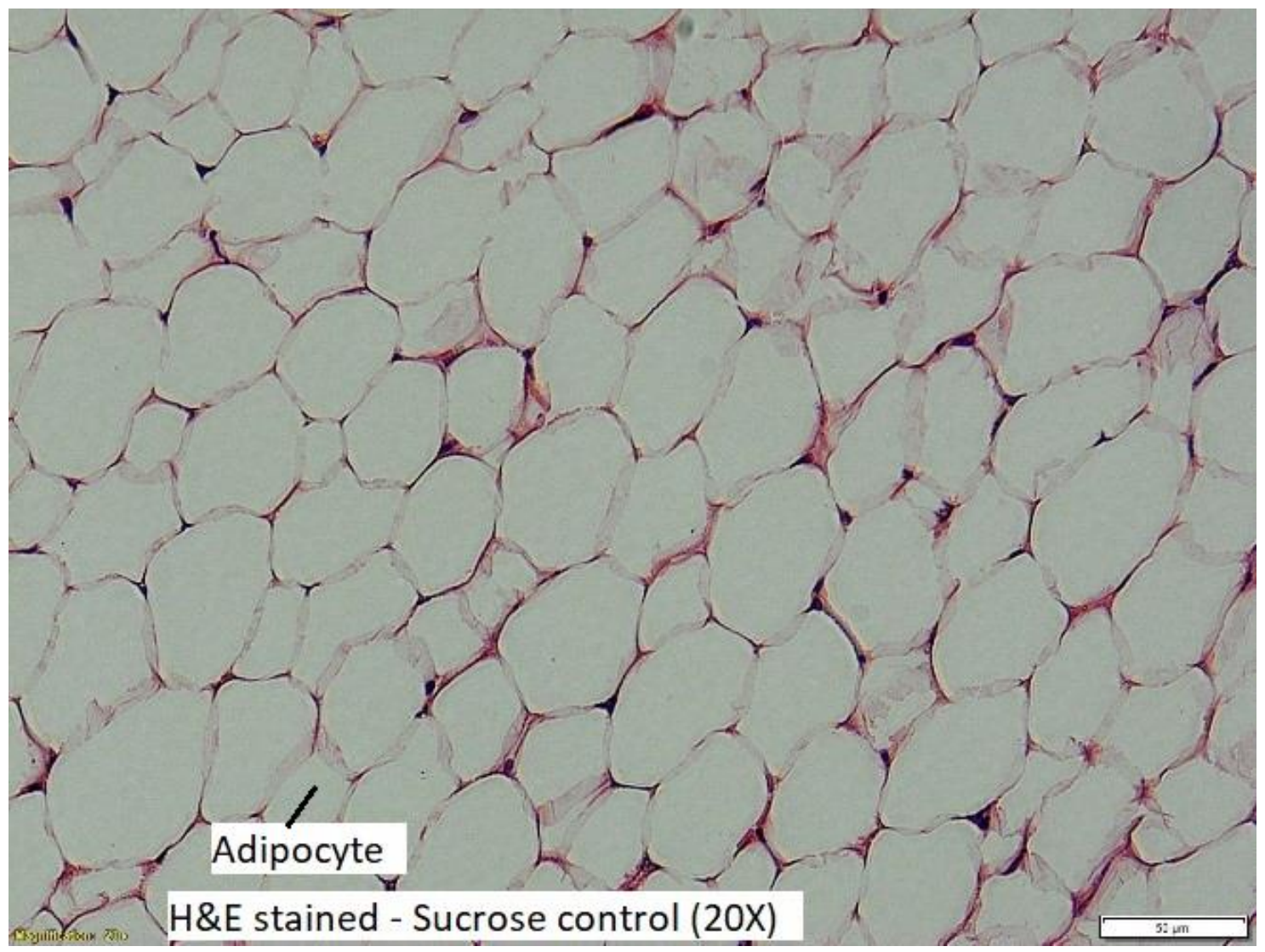

B

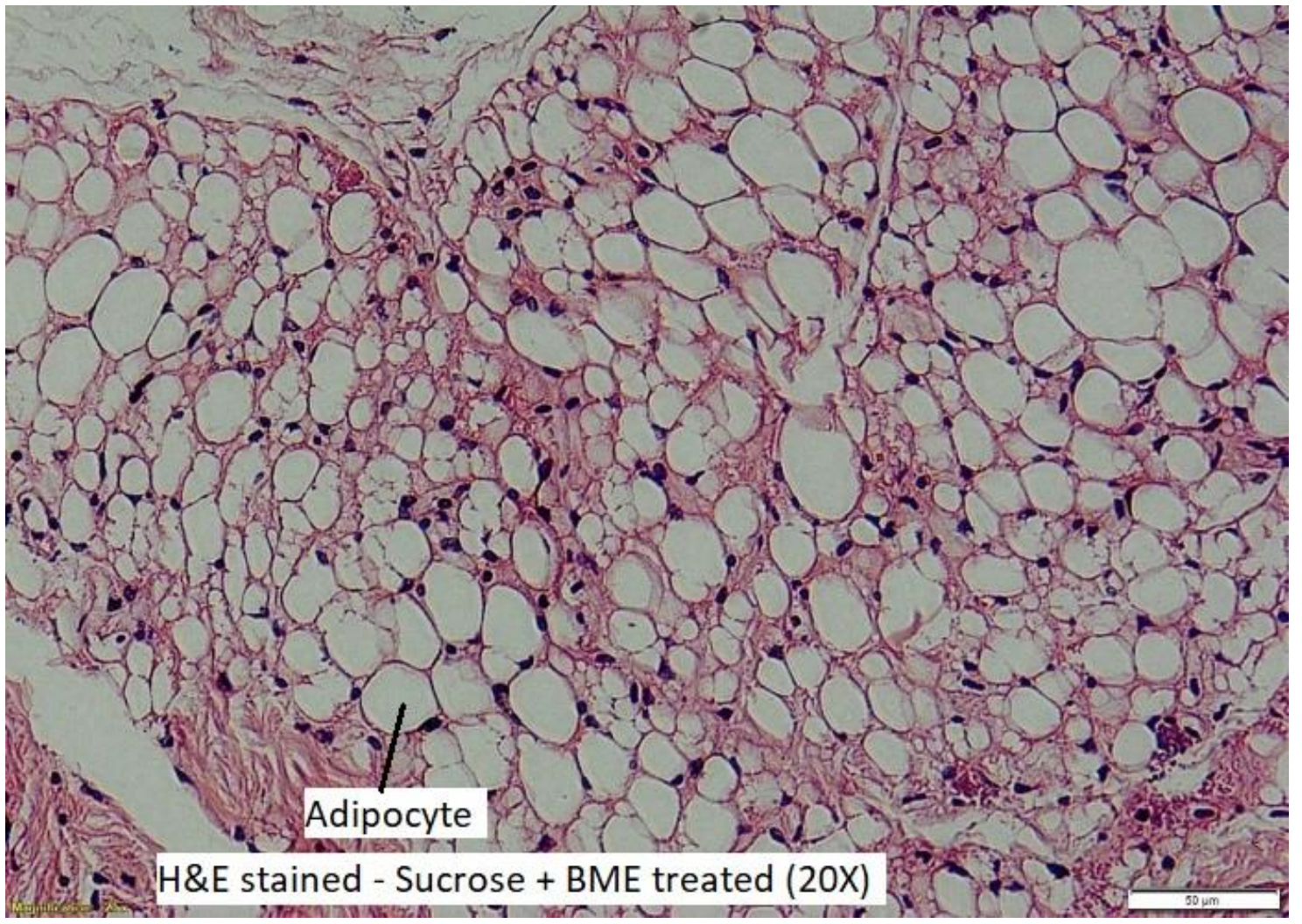

Figure 7. Retroperitoneal adipose tissue of mice treated with a $30 \%$ sucrose solution (20 X). (A) without BME supplementation; (B) with BME supplementation. 
A

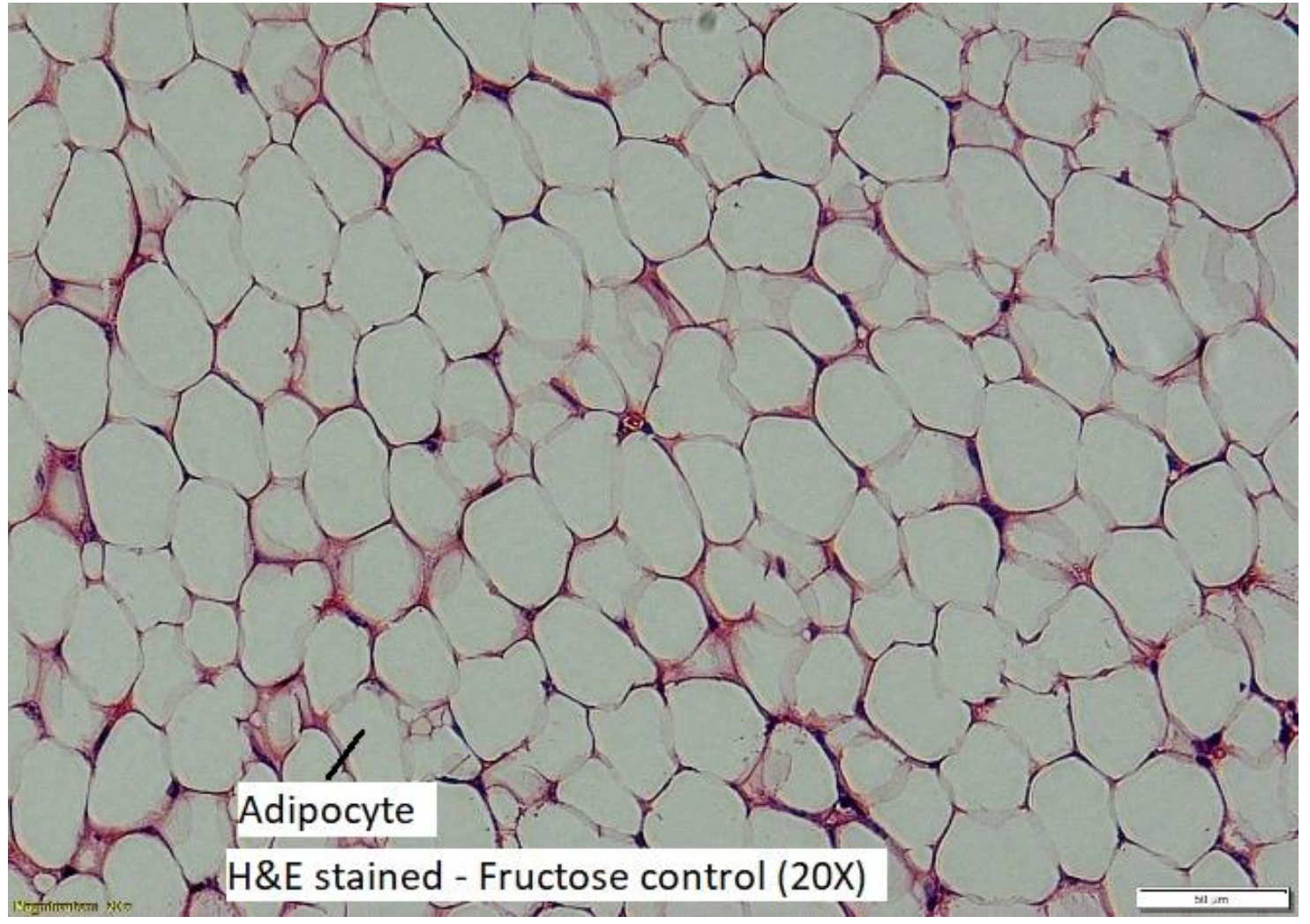

B

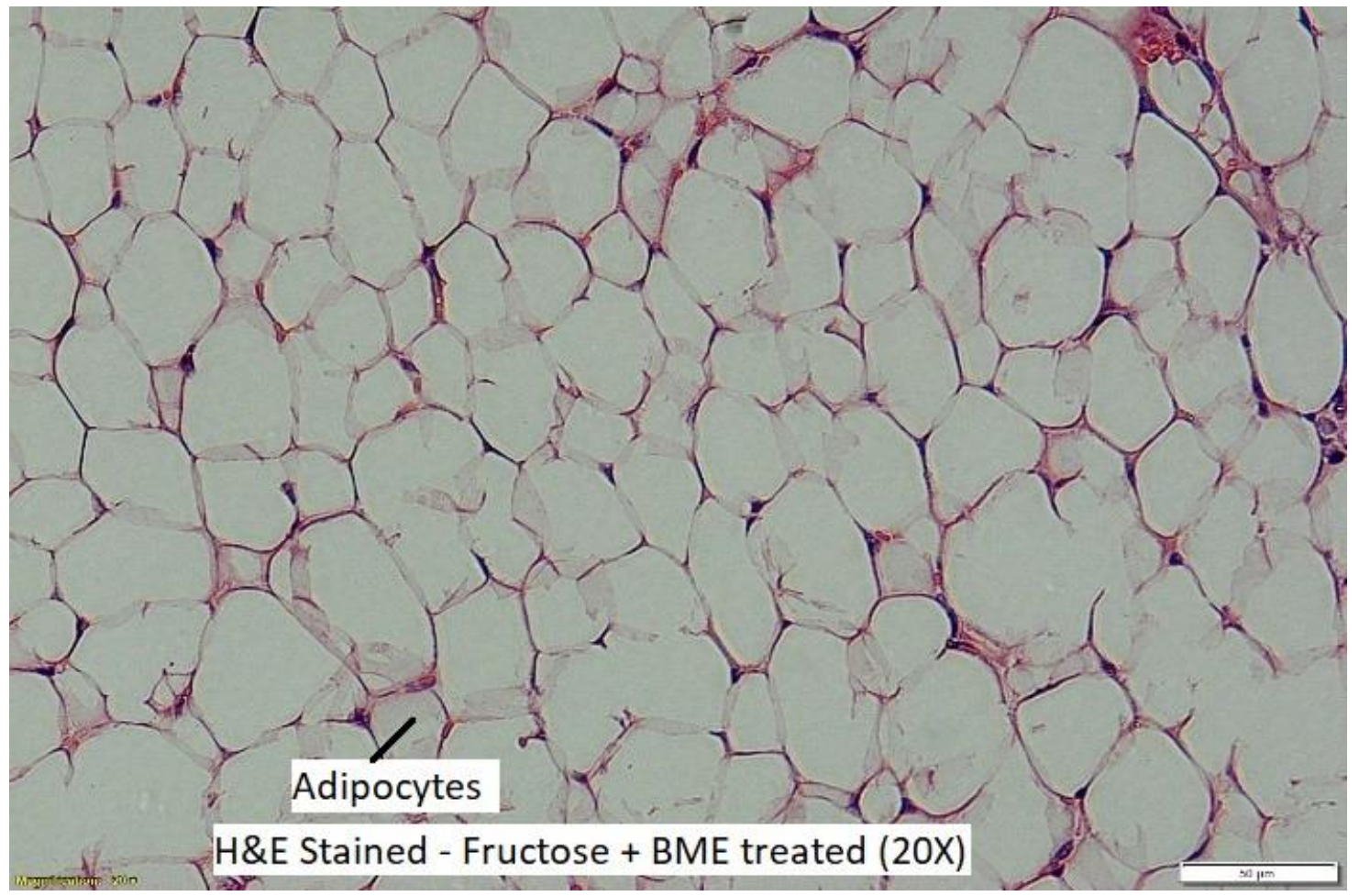

Figure 8. Retroperitoneal adipose tissue of mice treated with a $30 \%$ fructose solution (20 X). (A) without BME supplementation; (B) with BME supplementation. 


\section{DISCUSSION}

A global public health crisis may result due to the widespread epidemic of obesity and diabetes mellitus that has affected industrialized as well as developing nations. Fructose is extensively present in the modern diet and its increased consumption has become a major public health concern. Consumption of excess sugars in the diet is associated with increased body mass index (BMI), insulin resistance, dyslipidemia, cardiovascular episodes, as well as type 2 diabetes mellitus (Elliott et al., 2002). Studies that have explored the direct effects of fructose consumption in animals and humans have shown dyslipidemia, hypertension, insulin resistance, and glucose intolerance. Plant metabolites have shown promising results in reversing the harmful effects of a high sugar diet thus combating insulin resistance, weight gain, and metabolic syndrome. In this study, we have demonstrated that Bitter melon has a hypoglycemic and hypolipidemic activity that may help to reduce the body weight and reverse the features of metabolic syndrome induced by increased consumption of sugary beverages.

Bitter melon contains several phytochemicals that have shown several health benefits and extracts of this plant have shown to reduce visceral obesity with excellent antidiabetic and antioxidant activities (Mahmoud et al., 2017). Researchers have also shown that these bioactive compounds have a hypolipidemic activity that can lower serum and liver cholesterol, by reducing the reabsorption of bile acids into the intestine and increasing its synthesis from cholesterol by enhancing the expression of CYP7A1 (Matsui et al., 2013). However, these studies were carried out on rats fed with high cholesterol diet. We wanted to check if a similar activity is shown by bitter melon when the metabolic syndrome is induced by high sugar beverages. We monitored the body weight and blood sugar levels through the 8 weeks and lipid profile, adipocyte cell count, and cell size at the end of the 8th week in the study.

\section{Bitter melon extract and its effect on body weight}

A gradual increase in the body weight was observed during the first 4 weeks in both the controls and those supplemented with high sugars. However, the weight gain was less in the mice supplemented with sucrose and fructose. Previous studies have shown that high glucose and fructose drinking mice for 10 weeks had gained a similar amount of weight along with the fat accumulation in the liver when compared to the control mice when they ate a standard, low-fat diet, and water. However, when the mice ate a high-fat diet there was more weight gain, reduced glucose tolerance, and impaired insulin signaling upon high fructose consumption (NIDDK, no date). A significant increase in BMI was observed in male rats following induction with $66 \% \mathrm{wt} / \mathrm{vol}$ of fructose for 6 weeks when compared to normal controls (Subramani and Krishnamurthy, 2019). In our study, we have induced the mice for 4 weeks with high sugar beverages and that could be one of the reasons for not seeing a significant difference in the increase of the bodyweight when compared to the controls.

Upon treating the mice with BME, a significant reduction of the body weight was observed in mice induced with high glucose, fructose, and sucrose. Several studies have shown that BME can decrease body weight in obesity induced by a high-fat diet in model organisms (Alam et al., 2015). It reduced the retroperitoneal fat deposition, reduced the weights of visceral fat, and epidydimal white adipose tissue in high-fat diet-induced obese animals. Numerous mechanisms have been proposed to lower body weight by bitter melon supplementation. It was suggested that decreased adiposity after BME supplementation may be due to reduced metabolic efficiency as a consequence of increased oxidation of lipids and uncoupling in the mitochondria. This has been proved by demonstrating increased levels of mitochondrial carnitine palmitoyltransferase- 1 and acyl-CoA dehydrogenase enzyme in the liver and skeletal muscle (Chan et al., 2005). However, Saeed et al. (2017) showed slightly reduced body weight only in rats on a normal diet while rats fed with sucrose and cholesterol showed increased weight in the group treated with BME when compared to the respective control group (Saeed et al., 2017). 


\section{Bitter melon extract and its effect on blood glucose levels}

The blood glucose levels gradually increased during the induction phase of the first 4 weeks. During the treatment phase i.e. next 4 weeks, the blood sugar levels decreased significantly in groups 3, 5, and 7 who received BME supplementation. Studies have shown that chronic intake of high sucrose diet for 55 weeks increased intestinal sucrase activity but not hepatic glucose-6-phosphatase activity suggesting that glucose intolerance is not due to hepatic gluconeogenesis but due to reduction in the early insulin secretion from the pancreatic islets (Sumiyoshi, Sakanaka and Kimura, 2006). Several investigations have been carried out to assess the effectiveness of bitter melon in the management of diabetes mellitus. Malekshahi et.al. reported a significant reduction in blood glucose levels in diabetic rats when treated with BME at 20\% concentration for 6 weeks (Malekshahi et al., 2019). They demonstrated an increased expression of the insulin gene that is required to produce insulin to control the blood glucose levels and increased expression of PDX1 which is the main transcription factor in the development of the pancreas. Fachinan et al. (2017) showed that bitter melon induced a significant reduction in blood glucose in type 1 diabetic rats. They observed a significant decrease in plasma IL-2 and IFN- $\gamma$ with a significant increase in IL-4 and IL10 in diabetic rats treated with bitter melon. They concluded that the antioxidant compounds present in bitter melon induced the shift of proinflammatory Th1 phenotype in diabetic rats towards a favorable anti-inflammatory Th2 status (Fachinan et al., 2017). Our study has also shown the presence of antioxidant and anti-inflammatory properties in the bitter melon extract through FRAP, DPPH, and HRBC membrane-stabilizing assays which could be the reason for the lowering the levels of blood glucose. Choudhary et al. (2012) evaluated the antihyperglycemic activity of fractionated bitter melon seed extracts in alloxaninduced diabetic rats and showed a maximum decrease in the levels of blood glucose by the Mc3 soluble fraction obtained after differential salt precipitation. Increased liver and muscle glycogen content suggested that the anti-hyperglycemic activity was due to the increased synthesis of glycogen and decreased activity of glycogen phosphorylase (Choudhary et al., 2012).

\section{Bitter melon extract and its effect on lipid profile parameters}

A significant increase in the TC, TGL, LDL, and VLDL was observed upon induction with high sugar beverages, and treatment with BME was successful in reducing these levels. Saeed et al. (2017) showed a significant reduction in TC, LDL, and TGL levels from the beginning till the closure of the study in groups that was fed with a bitter melon powder-containing diet (Saeed et al., 2017). Significant improvement in the serum lipid profile parameters was observed by AbdelRahman et al. (2019) in diabetic rats treated with BME when compared to the diabetic control group (Abdel-Rahman et al., 2019). Increased insulin secretion from the beta cells of the pancreas, induced by bitter melon, stimulates the synthesis of fatty acids and incorporates the fatty acids into triglycerides in the adipose tissue and liver. In primary human preadipocytes, Nerurkar et al. (2010) investigated the effects of the BME on lipid accumulation and transcription factors inducing adipocyte differentiation. He reported a reduction in lipid content on treating preadipocytes with variable concentrations of BME during differentiation. Reduced mRNA expression of adipocyte transcription factors such as peroxisome proliferator-associated receptor $\gamma$ $(\operatorname{PPAR} \gamma)$ and sterol regulatory element-binding protein 1c (SREBP-1c) and adipocytokine, resistin was also noted. These genes play an important role in cellular lipid droplet accumulation, differentiation of adipocytes, and adipogenesis (Nerurkar et al., 2010). Hussain et al. (2019) reported an increase in serum TC and TG levels in the high-fat diet (HFD) group than in the control. After 21 days of treatment with bitter melon at a dose of $200 \mathrm{mg} / \mathrm{kg}$ body weight along with HFD showed a significant decrease in TC and TGL when compared to the $20 \%$ fat group (Hussain et al., 2019). Supplementation with bitter melon extract, downregulated the hepatic Liver X receptor (LXR) $\alpha$ expression which was responsible for the decreased serum TC, LDL, and HDL in Wistar rats fed with high cholesterol diet (Matsui et al., 2013). LXR is known to play a crucial role in lipid and cholesterol metabolism as $L X R \alpha$ knockout mice developed fatty liver and 
elevated cholesterol levels when fed a highcholesterol diet (Schulman, 2017).

\section{Bitter melon extract and its effect on adipose tissue}

There was an increased deposition of lipid content in the adipocytes of the mice belonging to groups 2,4 , and 6 upon induction with high sugar beverages when compared to the control group. This was reflected by the increased adipocyte cell size resulting in a decreased number of cells per high power field. On treatment with BME, there was a significant attenuation and reversal of lipid deposition in groups 3 and 5 which was reflected by the decrease in the adipocyte cell size and increase in the number of cells per high power field. However, there was no decrease in the size of the adipocytes after treatment with BME in mice induced with high fructose. Bao et. al. have also shown that diet supplemented with BM could decrease HFD-induced body weight gain and related hyperplasia of adipose tissue. They also studied the detailed inflammatory profile including macrophages, mast cells, and few proinflammatory cytokines in epidydimal adipose tissue, subcutaneous adipose tissue, and brown adipose tissue in mice fed with a high and low-fat diet with and without BME supplementation. Macrophage infiltration into epidydimal adipose tissue and brown adipose tissue was reduced by BME, which also altered the M1/M2 phenotype ratio of macrophages in these tissues. BME significantly decreased the number of mast cells in epidydimal adipose tissue in mice fed with HFD and increased the mRNA expression of gene Ucp1 (marker gene for energy expenditure) in brown adipose tissue in mice fed with HFD. Hence, it may be suggested that BME reduces lipid deposition by repressing mast cell infiltration and increasing energy expenditure (Bao et al., 2013). However, further studies are required to understand why treatment with BME was not effective in mice induced with high fructose beverages. The limitation of the study is that the possible bioactive compound present in the extract could not be identified, we plan to further extend the study to meet this objective.

\section{CONCLUSION}

In summary, our results show that high sugar beverages induce weight gain, increases blood glucose, deranges the lipid profile, and also induces adipocyte hypertrophy. Bitter melon extract, due to the presence of high phenolic acids and high antioxidant and anti-inflammatory properties has several health benefits. This in-vivo study on mice has shown that BME can decrease the weight and blood sugar levels in those induced with high sugar beverages. It also improves the lipid profile by decreasing the TC, TGL, LDL, and VLDL levels and reduces the adipocyte hypertrophy induced by high glucose and sucrose beverages.

\section{ACKNOWLEDGEMENTS}

We would like to acknowledge the JSS Academy of Higher Education \& Research for providing financial assistance for the study (REG/DIR(R)/URG/54/2011-12 dated 16-012019). We also would like to thank DST-FIST and VGST for funding the CEMR laboratory which enabled us to carry out the work.

\section{CONFLICT OF INTERESTS}

The authors have declared that no conflict of interest exists.

\section{REFERENCES}

A tale of two sugars-fructose and glucose cause differing metabolic effects. NIDDK. Available at: https://www.niddk.nih.gov/news/ archive/2017/taletwo-sugars-fructose-glucose-cause-differing-metaboliceffects (Accessed: June 13, 2021).

Abdel-Rahman, R. F., Soliman, G. A., Saeedan, A. S., Ogaly, H. A., Abd-Elsalam, R. M., Alqasoumi, S. I., \& Abdel-Kader, M. 2019. Molecular and biochemical monitoring of the possible herb-drug interaction between Momordica charantia extract and glibenclamide in diabetic rats. Saudi Pharmaceutical Journal 27(6): 803-816.

Adiels, M., Olofsson, S. O., Taskinen, M. R., \& Borén, J. 2008. Overproduction of very low-density lipoproteins is the hallmark of the dyslipidemia in the metabolic syndrome. 
Arteriosclerosis, Thrombosis, and Vascular Biology 28(7): 1225 1236.

Alam, M. A., Uddin, R., Subhan, N., Rahman, M. M., Jain, P., \& Reza, H. M. 2015. Beneficial role of bitter melon supplementation in obesity and related complications in metabolic syndrome. Journal of Lipids 2015: 1-18.

Bao, B., Chen, Y. G., Zhang, L., Na Xu, Y. L., Wang, X., Liu, J., \& $\mathrm{Qu}, \mathrm{W}$. 2013. Momordica charantia (bitter melon) reduces obesity-associated macrophage and mast cell infiltration as well as inflammatory cytokine expression in adipose tissues. PLOS ONE 8(12): e84075.

Bayya, M. H. R. K. G., Sachidananda A. M. N., Nagendra N. I. M., Asitava, D. R., \& Sampath, K. A. K. 2018. Evaluation of reversal effects of Eugenia jambolana seed extracts against high-fructose diet-induced insulin resistance in albino rats. Asian Journal of Pharmaceutical and Clinical Research 11(12): 572-576.

Bray, G. A. 2013. Energy and fructose from beverages sweetened with sugar or high-fructose corn syrup pose a health risk for some people. Advances in Nutrition 4(2): 220-225.

Chan, L. L., Chen, Q., Go, A. G., Lam, E. K., \& Li, E. T. 2005. Reduced adiposity in bitter melon (Momordica charantia)-fed rats is associated with increased lipid oxidative enzyme activities and uncoupling protein expression. Journal of Nutrition 135(11): 2517-2523.

Chandru, S., Vishwanath, P., Devegowda, D., Ramasamudra, S. N., Prashant, A., \& Hathur, B. 2016. Evaluation of protein kinase $\mathrm{C} \beta$ and PPAR $\gamma$ activity in diabetic rats supplemented with Momordica charantia. Journal of Clinical and Diagnostic Research 10(4): BF01-BF04.

Choudhary, S. K., Chhabra, G., Sharma, D., Vashishta, A., Ohri, S., \& Dixit, A. 2012. Comprehensive evaluation of antihyperglycemic activity of fractionated Momordica charantia seed extract in alloxan-induced diabetic rats. Evidence-based Complementary and Alternative Medicine 2012: 293650.

Elliott, S. S., Keim, N. L., Stern, J. S., Teff, K., \& Havel, P. J. 2002. Fructose, weight gain, and the insulin resistance syndrome. American Journal of Clinical Nutrition, 76(5): 911-922.

Fachinan, R. Yessoufou, A., Nekoua, M. P., \& Moutairou, K. 2017. Effectiveness of antihyperglycemic effect of Momordica charantia: Implication of T-Cell cytokines. Evidence-based Complementary and Alternative Medicine 2017: 3707046.

Gad, S. E. \& Sullivan, D. W. 2014. Dimethyl sulfoxide (DMSO) in Encyclopedia of Toxicology: Third Edition. Elsevier, pp. 166-168.

Hannou, S. A., Haslam, D. E., McKeown, N. M., \& Herman, M. A. 2018. Fructose metabolism and metabolic disease. Journal of Clinical Investigation 128(2): 545-555.

Hussain, M. S., Jahan, N., Rashid, M. M. O., Hossain, M. S., Chen, U., \& Rahman, N. 2019. Antihyperlipidemic screening and plasma uric acid reducing potential of Momordica charantia seeds on Swiss albino mice model. Heliyon 5(5): e01739.

Kit, B. K., Fakhouri, T. H., Park, S., Nielsen, S. J., \& Ogden, C. L. 2013. Trends in sugar-sweetened beverage consumption among youth and adults in the United States: 1999-2010. American Journal of Clinical Nutrition 98(1): 180-188.

Kolderup, A. \& Svihus, B. 2015. Fructose metabolism and relation to atherosclerosis, type 2 diabetes, and obesity. Journal of Nutrition and Metabolism 2015: 823081.

Krans, H. M. J. 1994. Insulin, glucagon, and oral hypoglycemic drugs. Side Effects of Drugs Annual 18(C): 409-420.

Mahmoud, M. F., El Ashry, F. E. Z. Z., El Maraghy, N. N., \& Fahmy, A. 2017. Studies on the antidiabetic activities of Momordica charantia fruit juice in streptozotocin-induced diabetic rats. Pharmacentical Biology 55(1): 758-765.

Malekshahi, H., Bahrami, G., Miraghaee, S., Ahmadi, S. A., Sajadimajd, S., Hatami, R., Mohammadi, B., \& Keshavarzi, S. 2019. Momordica charantia reverses type II diabetes in rat. Journal of Food Biochemistry 43(11): e13021.
Matsui, S., Yamane, T., Takita, T., Oishi, Y., \& Kobayashi-Hattori, K. 2013. The hypocholesterolemic activity of Momordica charantia fruit is mediated by the altered cholesterol- and bile acid-regulating gene expression in rat liver. Nutrition Research 33(7): 580-585.

Nerurkar, P. V., Lee, Y. K., \& Nerurkar, V. R. 2010. Momordica charantia (bitter melon) inhibits primary human adipocyte differentiation by modulating adipogenic genes. $B M C$ Complementary and Alternative Medicine 10: 34.

Ng, Z. X. \& Kuppusamy, U. R. 2019. Effects of different heat treatments on the antioxidant activity and ascorbic acid content of bitter melon, Momordica charantia. Brazilian Journal of Food Technology 22: e2018283.

Raben, A., Vasilaras, T. H., Møller, A. C., Astrup, A. 2002. Sucrose compared with artificial sweeteners: Different effects on ad libitum food intake and body weight after $10 \mathrm{wk}$ of supplementation in overweight subjects. American Journal of Clinical Nutrition 76(4): 721-729.

Saeed, F., Arshad, M. S., un Nisa, M., Nadeem, M. T., \& Arshad, M. U. 2017. Hypoglycemic and hypolipidemic effects of different parts and formulations of bitter gourd (Momordica Charantia). Lipids in Health and Disease 16(1): 211.

Saeed, F., Sultan, M. T., Riaz, A., Ahmed, S., Bigiu, N., Amarowicz, R., \& Manea, R. 2021. Bitter melon (Momordica charantia L.) fruit bioactives charantin and vicine potential for diabetes prophylaxis and treatment. Plants 10(4): 730.

Schulman, I. G. 2017. Liver X receptors link lipid metabolism and inflammation. FEBS Letters 591(19): 2978-2991.

Shobha, C. R., Prashant, V., Akila, P., Chandini, R., Suma, M. N., \& Basavanagowdappa, H. 2017. Fifty percent ethanolic extract of Momordica charantia inhibits adipogenesis and promotes adipolysis in 3T3-L1 pre-adipocyte cells. Reports of Biochemistry and Molecular Biology 6(1): 22-31.

Sievenpiper, J. L., de Souza, R. J., Adrian, I., Cozma, L., Ha, V., \& Mirrahimi, A. 2014. Fructose vs. glucose and metabolism: Do the metabolic differences matter?. Current Opinion in Lipidology 25(1): 8-19.

Stanhope, K. L. 2016. Sugar consumption, metabolic disease and obesity: The state of the controversy. Critical Reviews in Clinical Laboratory Sciences 53(1): 52-67.

Subramani, B. \& Krishnamurthy, B. 2019. Effects of Momordica charantia (bitter gourd) on oxidative stress and proinflammatory marker in metabolic syndrome using a highfructose diet induced rat model. Biomedical and Pharmacology Journal 12(1): 305-324.

Sumiyoshi, M., Sakanaka, M., \& Kimura, Y. 2006. Chronic intake of high-fat and high-sucrose diets differentially affects glucose intolerance in mice. Journal of Nutrition 136(3): 582587.

Thorburn, A. W., Storlien, L. H., Jenkins, A. B., Khouri, S., \& Kraegen, E. W. 1989. Fructose-induced in vivo insulin resistance and elevated plasma triglyceride levels in rats. American Journal of Clinical Nutrition 49(6): 1155-1163.

Truswell, A. S., Seach, J. M., \& Thorburn, A. W. 1988. Incomplete absorption of pure fructose in healthy subjects and the facilitating effect of glucose. American Journal of Clinical Nutrition 48(6): 1424-1430. 